\title{
Peningkatan Kinerja Organisasi TI Berdasarkan Metode DMAIC Dengan Pendekatan Frame Work ITIL V.3
}

\author{
${ }^{1}$ Alvian Guntur Perdana Kusuma, ${ }^{2}$ Wahyudi Hidayat \\ Widyaiswara Ahli Pertama Kementerian Perhubungan; IT Supervisor Supernova \\ Group \\ Email: $\underline{1}$ alvianguntur0@gmail.com, ${ }^{2}$ wahyudi.hidayat@supernova-id.com
}

(Diterima: Juli 2021; Direvisi: Juli 2021; Dipublikasikan: September 2021)

\begin{abstract}
ABSTRAK
Dalam upaya untuk memberikan layanan TI yang baik dan berkualitas guna mendukung jalannya bisnis proses perusahaan, kemungkinan pencapaian tujuan pemberian layanan TI yang baik dan berkualitas dapat tidak tercapai. Salah satu indikator pencapaian layanan TI tersebut maksimal adalah tercapainya indeks kepuasan pengguna internal terhadap penggunaan layanan TI tersebut. Buruknya indeks pencapaian kepuasan pengguna tersebut dapat disebabkan oleh banyak faktor, salah satunya adalah kinerja organisasi TI. Jenis Penelitan adalah kuantitatif kualitatif dengan desain penelitian adalah deskriptif. Tujuan penelitian adalah untuk mengetahui hal-hal yang mempengaruhi buruknya indeks pencapaian kepuasan pengguna layanan TI dan bagaimana mendapatkan improvement yang tepat, ditinjau dari sisi service operation di organisasi TI Supernova Group. Dilakukan dengan melaksanakan focus group discussion dengan manajemen organisasi TI Supernova Group dan hasil yang diperoleh dianalisa dengan metode DMAIC dengan menggunakan acuan baku ITSM, frame work ITIL v.3. Kesimpulan adalah buruknya indeks pencapaian kepuasan pengguna layanan TI Supernova Group adalah disebabkan tidak adanya beberapa hal berikut, tidak adanya OLA \& UC untuk semua layanan, tidak adanya KEDB, tidak adanya problem management, tidak adanya configuration management, kurangnya informasi insiden yang diterima melalui telepon, kurangnya pelatihan serta tidak adanya panduan untuk menentukan prioritas insiden. Hasil improvement adalah adanya peningkatan resolusi penanganan insiden dari 7.686 jam menjadi 4.884 jam serta IT maturity dari incident $\&$ problem management process dan service desk function dari $0,1.5$, 1.5 menjadi $1.5,1.5,2.5$.
\end{abstract}

\section{Kata Kunci: Kepuasan Pengguna, Layanan TI, Faktor-Faktor Penyebab Buruknya Kepuasan Pengguna, DMAIC, ITIL v.3}




\section{PENDAHULUAN}

Seiring dengan semakin berkembangnya bisnis pada sebuah perusahaan maka pada umumnya tingkat kompleksitas teknologi informasi (TI) yang dimilikinya akan semakin bertambah juga. Jika sebelumnya banyak organisasi TI hanya berfokus pada masalah teknis, maka pada saat ini sudah semakin banyak organisasi TI yang berubah dan lebih berfokus kepada memberikan layanan TI yang berkualitas tinggi, dan hal ini menjadi suatu tantangan bagi para eksekutif dan manajer TI. Organisasi TI dalam suatu perusahaan dituntut agar dapat memberikan kontribusi secara maksimal terhadap jalannya bisnis proses perusahaan. Organisasi TI saat ini sudah harus berorientasi terhadap bagaimana cara untuk dapat allignment dengan visi dan misi perusahaan. Organisasi TI sudah harus menjadi organisasi yang berfungsi sebagai core business.

Supernova Group adalah sebuah perusahaan yang bergerak di bidang manufaktur flexible packaging di Indonesia, dimana organisasi TI di dalamnya mempunyai 18 orang karyawan TI (dibagi ke dalam 3 divisi: IT Business Capabilities Planning \& Delivery, IT Operation Management, dan IT Service Management) yang melayani lebih dari 1000 pengguna layanan TI yang tersebar di 4 plant, antara lain Kawasan Industri Ancol, Kawasan Industri MM2100, Kawasan Industri Jababeka II dan Jababeka VI.

Dalam hal manajemen operasi dan layanan di organisasi TI Supernova Group, banyak hal dari pengguna yang belum mendapatkan kepuasan terbaik dari layanan yang organisasi TI berikan. Sejak manajemen baru terbentuk (manajemen sebelumnya masih menginduk kepada PT Indopoly Swakarsa Industri, Tbk., manajemen mandiri Supernova Group terbentuk pada semester II tahun 2014), manajemen memberikan target pencapaian kepuasan pengguna sebesar $80 \%$ terhadap layanan TI yang akan dievaluasi setiap triwulannya. Sejak target tersebut dicanangkan pada awal Januari 2019 sampai dengan akhir Juni 2020 (dievaluasi per triwulan), didapat hasil bahwa realisasi kepuasan pengguna terhadap layanan TI selalu di bawah target yang diharapkan manajemen (bahkan menunjukkan tren penurunan). Gambar 1 menunjukkan target manajemen dalam hal kepuasan pengguna terhadap layanan TI vs realisasi hasil survey kepuasan pengguna terhadap layanan TI per triwulan. 


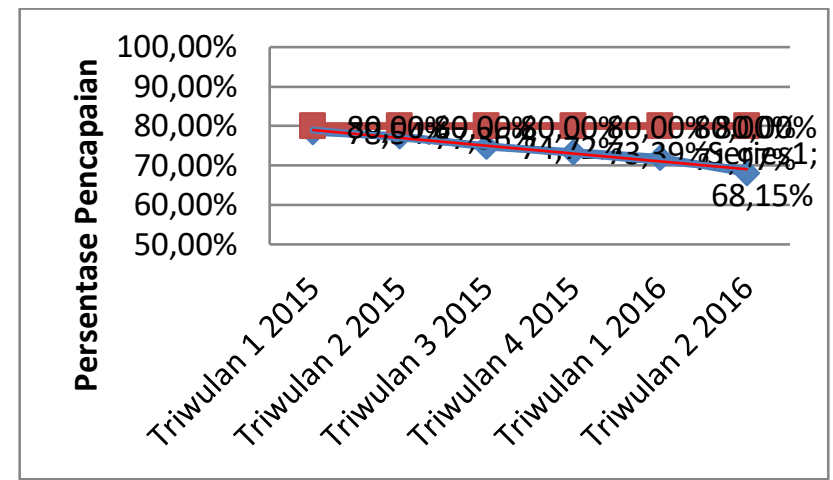

Gambar 1. Target Manajemen vs Realisasi Kepuasan Pengguna Sumber: Supernova Group/IST Dept, 2020

Dari gambar di atas menunjukkan bahwa terus terjadi penurunan kepuasan pengguna terhadap layanan TI dari periode evaluasi pertama sampai dengan periode evaluasi terakhir. Sejak awal Januari 2019 sampai dengan akhir Juni 2020, menunjukkan semakin besar GAP yang dihasilkan antara target manajemen dalam hal pencapaian kepuasan pengguna terhadap layanan TI dibandingkan dengan realisasinya.

Untuk mendapatkan gambaran terkait hal yang menyebabkan buruknya pencapaian kepuasan pengguna terhadap layanan TI, manajemen organisasi TI Supernova Group melakukan assesment tambahan terkait hal di atas, yang isinya ditambahkan di dalam form survei kepuasan pengguna pada periode evaluasi triwulan kedua tahun 2020. Berikut digambarkan dalam Gambar 2 mengenai penyebab/alasan pengguna layanan TI di Supernova Group kurang/tidak puas terhadap layanan TI.

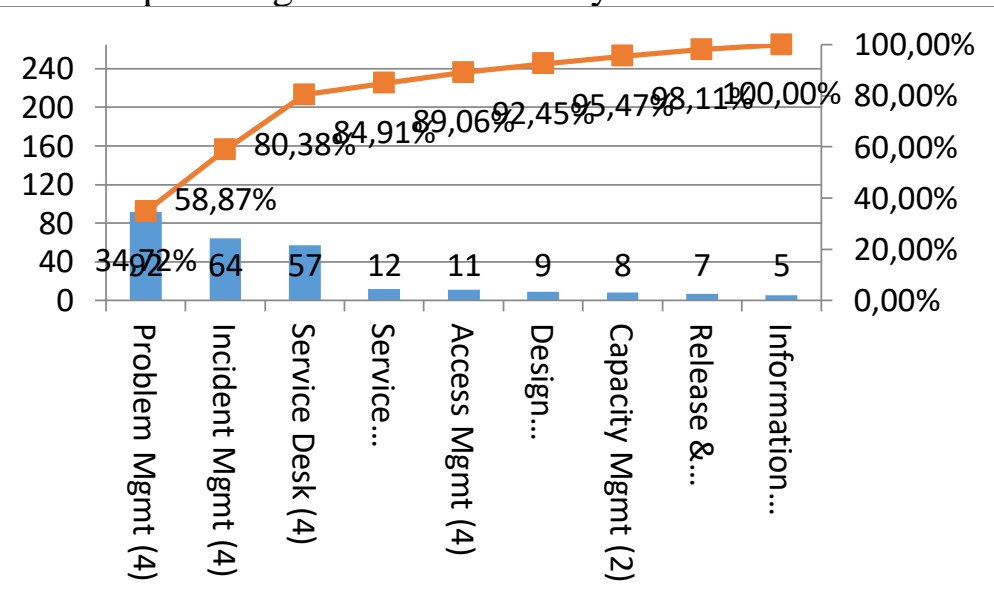

Gambar 2. Pareto Hasil Survei Triwulan II Tahun 2020 Penyebab Ketidakpuasan Pengguna Terhadap Layanan TI

Sumber: Supernova Group/IST Dept, 2020

Tidak tercapainya target manajemen dalam hal kepuasan pengguna terhadap layanan TI, secara garis besar dari gambar di atas dapat ditinjau dari IT performance organisasi TI. Hasil pareto di atas 
menunjukkan bahwa penyebab masalah buruknya kinerja organisasi TI dalam hal penanganan layanan TI terhadap penggunanya, 3 terbesar disebabkan oleh buruknya problem management process, incident management process dan service desk function.

Penelitian terdahulu yang ditampilkan oleh Chan (2008) dan Aazadnia \& Fasanghari (2008) dengan hasil metode DMAIC dan frame work ITIL dapat digunakan bagi organisasi TI untuk dapat mendeliver layanan TI yang baik dan berkualitas, dan pada akhirnya berdampak tercapainya kepuasan pengguna. Dan dalam penelitian terdahulu yang dilakukan oleh Potgieter (2010) dan Cater-Steel (2006) menyimpulkan bahwa baik atau buruknya incident dan problem management serta fungsi service desk akan mempengaruhi baik atau buruknya kualitas layanan TI yang diberikan oleh organisasi TI, yang pada akhirnya pula akan berdampak terhadap pencapaian kepuasan pengguna layanan TI tersebut. Penelitian Potgieter (2010) dan CaterSteel (2006) juga menunjukkan baik atau buruknya incident dan problem management serta fungsi service desk dapat diukur dengan IT maturity dengan acuan konsep ITSM-SA.

Dalam penelitian ini, digunakan acuan standar IT Service Management, frame work ITIL v.3 untuk mendefinisikan dan mengukur GAP antara realisasi implementasi incident \& problem management process dan service desk function dibandingkan dengan standar literaturnya. Dilakukan dengan mengukur seberapa besar maturity fungsi service desk dan seberapa besar maturity proses incident \& problem management dengan menggunakan konsep ITSM-SA (IT Service Management SelfAssessment) yang pengukurannya didapat dengan mengadakan Focus Group Discussion (FGD) kepada manajemen TI. Dari hasil pengukuran 3 IT maturity di atas, maka akan didapatkan rekomendasi hal apa saja yang perlu dilakukan dan ditingkatkan untuk meningkatkan IT performance. Serta untuk mendapatkan process improvement yang tepat, peneliti menggunakan metode DMAIC, guna mendefiniskan permasalahan, mengukur tingkat permasalahan, menganalisa akar permasalahan, melakukan improvement terhadap permasalahan yang terjadi serta melakukan pengawasan dan review terhadap perbaikan yang sudah dilakukan.

\section{TINJAUAN PUSTAKA}

Menurut Simamora (2003) kinerja adalah ukuran keberhasilan organisasi dalam mencapai misinya. Sedangkan Shadily (2002), mengatakan kinerja atau performance adalah berdaya guna prestasi atau hasil. Wahyudi Kumorotomo (2006) memberikan batasan pada konsep kinerja organisasi publik setidaknya berkaitan erat dengan efisiensi, efektifitas, keadilan dan daya tanggap.

Pengukuran kinerja merupakan proses mencatat dan mengukur pencapaian pelaksanaan kegiatan dalam arah pencapaian misi (mission accomplish) melalui hasil- hasil yang ditampilkan berupa produk, jasa ataupun suatu proses, dengan spektrum indikator input, outputs, outcomes, benefits, dan impacts 
(Yuwono, et al, 2008). Setiap kegiatan organisasi harus dapat diukur dan dinyatakan keterkaitannya dengan pencapaian arah organisasi di masa yang akan datang yang dinyatakan dengan pencapaian visi dan misi organisasi. Menurut Soedjono (2005), Pengukuran kinerja juga bertujuan pokok untuk memotivasi karyawan dalam mencapai sasaran organisasi dan dalam mematuhi standar perilaku yang telah ditetapkan sebelumnya agar memberikan hasil yang diinginkan. Dengan demikian akan diperoleh manfaat yaitu organisasi dapat berjalan secara efektif dan efisien.

Keterkaitan tujuan bisnis, tujuan teknologi informasi dan proses TI didefinisikan mengacu pada kerangka frame work ITIL v.3. Kerangka kerja tersebut menghubungkan informasi yang dibutuhkan dalam bisnis sebagai penggerak tata kelola terhadap sasaran yang diinginkan dalam penyediaan layanan TI (Stanwick, et al, 2002).

Dalam buku The Business Value of IT (Harris, et al, 2004), Pengukuran kinerja TI akan mencakup pengukuran pada tujuan TI, tujuan proses dan tujuan aktivitas. Pemenuhan tujuan TI sendiri juga diukur melalui sebuah ukuran kinerja yang selanjutnya akan disebut sebagai outcome. Sedangkan pemenuhan tujuan proses beserta aktivitasaktivitas yang terlibat, akan diukur melalui indikator-indikator kinerja. Outcome pada tujuan TI menggambarkan ukuran dari hal-hal yang diekspektasikan bisnis melalui penyediaan layanan TI. Sedangkan indikator kinerja pada tujuan proses menggambarkan proses TI yang seperti apa yang harus diberikan sebagai dukungan terhadap tujuan TI.

Frame work ITIL $v .3$ berorientasi pada bisnis dan didesain dan dikerjakan tidak hanya oleh user dan auditor, tetapi juga sebuah panduan kemprehensif bagi pihak manajemen maupun pemilik bisnis proses tersebut (Cater-Steel, et al, 2006). Frame work ITIL v.3 memberikan sebuah maturity process untuk mengendalikan proses TI sehingga pihak manajemen dapat memetakan di mana posisi perusahaan tersebut, keadaan perusahaan sesuai tidaknya dengan class industry ataupun terhadap standar internasional, faktor kritikal sukses organisasi yang mendefinisikan prioritas manajemen TI yang harus didahulukan dan diimplementasikan atau dikendalikan, dan menetapkan key goal indicator dan key performance indicator untuk menjadi landasan tolak ukur bagi mengukur keberhasilan TI dalam mencapai tujuan dan kesesuaianya dengan kebijakan organisasi (AlShamy, et al, 2012).

ITIL merupakan bagian dari publikasi best practice untuk ITSM yang dibentuk oleh organisasi OGC (Office of Government Commerce) yang saat ini telah berubah menjadi cabinet office. Kerangka kerja ITIL dibentuk berdasarkan lima tahap siklus dari layanan, dan untuk setiap siklus hidup tersebut ITIL menyediakan core-publication yang berisikan panduan best practice. ITIL memberikan panduan bagi organisasi TI mengenai kualitas layanan TI, proses fungsi dan kapabilitas lainnya 
yang menunjang penyedia layanan tersebut.

ITSM self-assesment dikembangkan oleh OGC sebagai alat bantu untuk mengukur tingkat kematangan fungsi dari proses ITIL. ITSM self-assesment ini terdiri dari kumpulan pertanyaan yang dapat memperlihatkan area mana saja yang perlu untuk diperhatikan untuk meningkatkan proses ITIL secara keseluruhan (Gacenga, et al, 2011). Menurut Kang, et al, (2002), penilaian kematangan pada ITSM self-assesment menggunakan 9 tingkat kematangan yaitu:

Tabel 1. ITSM Self-Assesment Maturity Level

\begin{tabular}{|c|c|}
\hline Level & Penjelasan \\
\hline 1 & $\begin{array}{l}\text { Prerequisite, ascertains whether the minimum level of prerequisite items are } \\
\text { available to support the process activities }\end{array}$ \\
\hline 1.5 & $\begin{array}{l}\text { Management Intent, establishes whether there are organizational policy statements, } \\
\text { business objectives (or similar evidence of intent) providing both purpose and } \\
\text { guidance in the transformation or use of the prerequisite items. }\end{array}$ \\
\hline 2 & $\begin{array}{l}\text { Process Capability, examines the activities being carried out. The questions are } \\
\text { aimed at identifying whether a minimum set of activities are being performed. }\end{array}$ \\
\hline 2.5 & $\begin{array}{l}\text { Internal Integration seeks to ascertain whether the activities are integrated } \\
\text { sufficiently in order to fulfill the process intent. }\end{array}$ \\
\hline 3 & $\begin{array}{l}\text { Products, examines the actual output of the process to enquire whether all the } \\
\text { relevant products are being produced. }\end{array}$ \\
\hline 3.5 & $\begin{array}{l}\text { Quality Control, is concerned with the review and verification of the process output } \\
\text { to ensure that it is in keeping with the quality intent. }\end{array}$ \\
\hline 4 & $\begin{array}{l}\text { Management Information, is concerned with the governance of the process and } \\
\text { ensuring that there is adequate and timely information produced from the process in } \\
\text { order to support necessary management decisions. }\end{array}$ \\
\hline 4.5 & $\begin{array}{l}\text { External Integration, examines whether all the external interface and relationships } \\
\text { between the discrete process and other processes have been estabilished within the } \\
\text { organization. At this level, for IT service management, use of full ITIL terminology } \\
\text { may be expected. }\end{array}$ \\
\hline 5 & $\begin{array}{l}\text { Customer Interface, is primarily concerned with the on-going external review and } \\
\text { validation of the process to ensure that it remains optimized towards meeting the } \\
\text { needs of the customer. }\end{array}$ \\
\hline
\end{tabular}

Salah satu metode yang digunakan untuk meningkatkan proses ITIL adalah dengan cara mengukur terlebih dahulu tingkat kematangan proses yang sudah ada saat ini untuk kemudian dikaji apakah perlu ditingkatkan atau tidak. Dengan mengkaji tingkat kematangan proses yang sudah atau belum ada pada saat ini, selanjutnya akan dapat mengetahui dengan jelas dimana process improvement sebaiknya mulai dilakukan (AlShamy, et al, 2012).

Chan, et al (2009) menjelaskan lebih lanjut bahwa six sigma memiliki metode DMAIC. DMAIC adalah sebuah siklus improvement yang berbasis kepada data (performance data), yang digunakan untuk meningkatkan, mengoptimasi dan menstabilkan desain dan proses bisnis pada suatu perusahaan. Namun demikian, DMAIC tidak hanya milik six sigma dan dapat digunakan 
sebagai kerangka kerja untuk aplikasi improvement lainnya. DMAIC digunakan untuk meningkatkan proses atau produk yang sudah ada. Salah satu kelebihan dari metode six sigma adalah memiliki banyak tools yang dapat digunakan, namun sebaiknya hanya menggunakan tools yang dapat membantu"get the job done". Metode DMAIC yang disediakan oleh six sigma digunakan pada saat sebuah produk atau proses yang telah ada saat ini di dalam sebuah perusahaan tidak dapat memenuhi spesifikasi pelanggan atau tidak menunjukkan kinerja yang sesuai harapan (Chan, et al, 2009).

\section{METODE PENELITIAN}

Berikut digambarkan dalam Gambar 3, diagram alur dari penelitian ini.

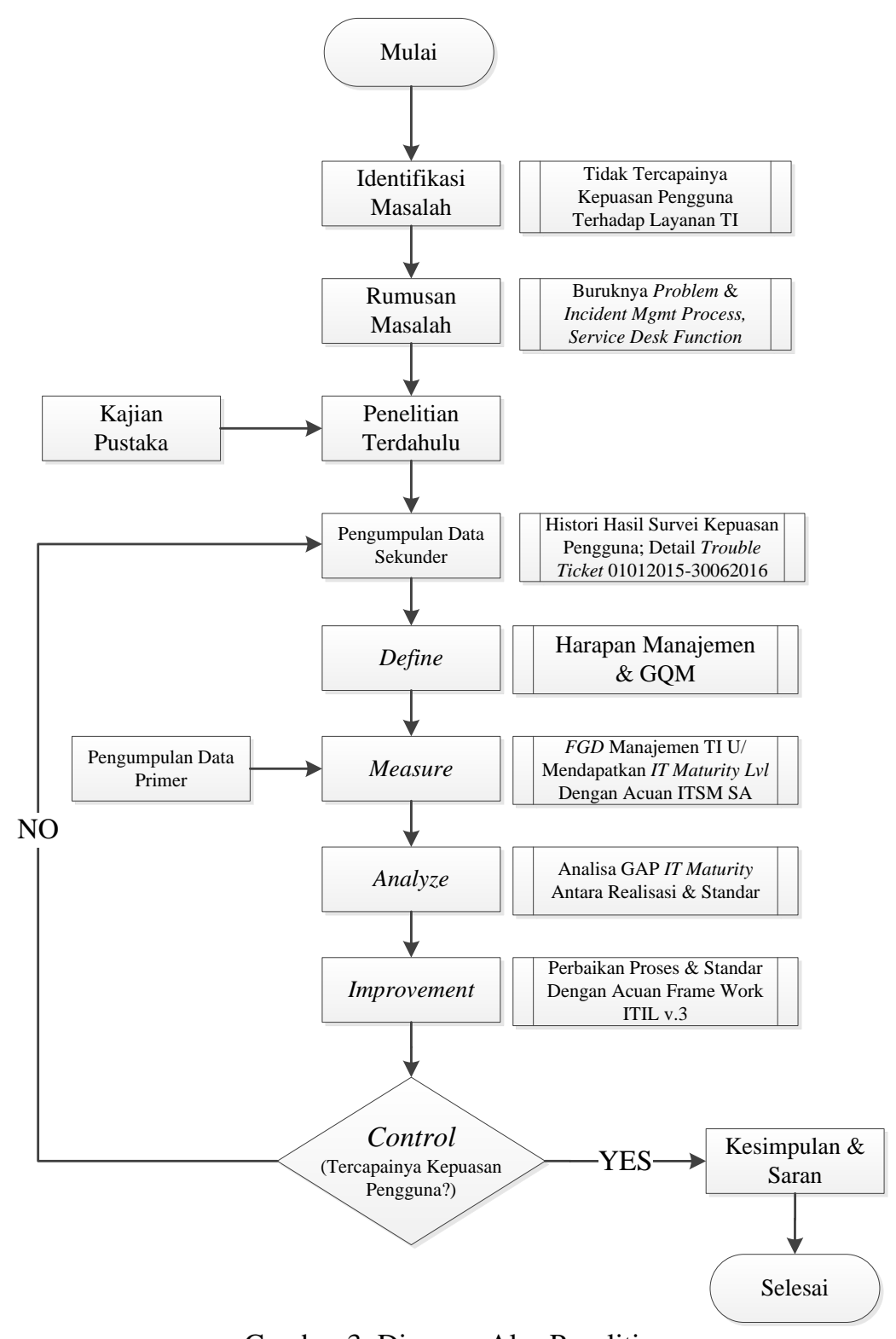

Gambar 3. Diagram Alur Penelitian

Sumber: Data diolah, 2020 
Jenis penelitian ini termasuk penelitian kuantitatif dan kualitatif. Penelitian kuantitatif karena bermaksud untuk mendapatkan IT maturity pada kondisi saat ini dan membandingkan dengan standar IT maturity yang direkomendasikan oleh acuan frame work ITIL v.3 lalu melakukan GAP analisis untuk mengetahui perbaikan seperti apa yang harus dilakukan. Penelitian kualitatif karena penelitian ini bersifat induktif, maksudnya adalah penelitian dilakukan berdasarkan kondisi empiris yang ada dan pada kesimpulannya berusaha untuk membangun sebuah konsep (dengan menggunakan dan acuan standar baku yang ada). Penelitian ini juga tidak menghasilkan jawaban benar atau salah, karena peneliti berusaha untuk membangun konsep dari kondisi empiris yang diamati. Sumber utama atau acuan dalam penelitian ini adalah dari penelitian-penelitian terdahulu. Penelitian ini menggunakan data primer yang didapat dari narasumber (informan) yang dilakukan dengan menggunakan teknik atau metode Focuss Group Discussion (FGD).

Variabel penelitian dari penelitian ini adalah kinerja organisasi TI di Supernova Group dengan tolok ukur pencapaiannya adalah indeks kepuasan pengguna internal. Secara rinci, indeks kepuasan pengguna internal tersebut oleh organisasi TI dapat diukur oleh 2 hal. Yaitu dengan diketahuinya baik/buruk pencapaian tingkat kematangan dari organisasi TI dan resolusi penanganan insiden/problem. Untuk mengidentifikasi atau menentukan faktor-faktor yang mempengaruhi buruknya kinerja organisasi TI tersebut adalah menggunakan salah satu standar baku implementasi ITSM, yaitu frame work ITIL v.3. Frame work ITIL v.3 merekomendasikan beberapa indikator atau tolok ukur yang dapat mempengaruhi baik buruknya kinerja organisasi TI dalam hal men-deliver layanan TI yang baik dan berkualitas. Hal ini juga didukung oleh penelitian terdahulu, menurut (Gacenga, et al, 2011) frame work ITIL v.3 dapat digunakan sebagai tolok ukur dan acuan untuk pengukuran IT Performance dan upaya untuk perbaikan atau peningkatannya. Dari hasil survei kepuasan pengguna triwulan kedua tahun 2020 terhadap seluruh karyawam Supernova Group (grade IV-VII) terkait upaya perbaikan kualitas kinerja organisasi TI itu sendiri dalam upaya akhir untuk meningkatkan kepuasan pengguna terhadap layanan TI, didapat 3 dimensi terbesar sebagai indikasi penyebab buruknya kinerja organisasi TI, antara lain, problem management process, incident management process, dan service desk function.

Data yang digunakan dalam penelitian ini adalah data primer dan data sekunder. Data primer yang dimaksud adalah dari hasil survei dalam panel diskusi focus group discussion terhadap seluruh manajemen TI dengan menggunakan konsep ITSM Self-Assesment untuk mendapatkan maturity dari masingmasing dimensi yang diteliti. Sedangkan data sekunder yang dimaksud adalah dari laporan hasil survei kepuasan pengguna TI terhadap layanan TI dari periode pengukuran triwulan pertama tahun 2019 sampai dengan triwulan kedua tahun 2020 dan data tiket insiden/problem berstatus close yang 
ada pada IT service portal yang terjadi selama kurun waktu awal tahun 2019 sampai dengan akhir Juni 2020, ditambah dengan dari berbagai studi kepustakaan diantaranya, data penelitian terdahulu, internet (jurnal penelitian internasional), dan literatur lain yang relevan dengan penelitian ini.

Data yang digunakan untuk pengukuran kinerja organisasi TI adalah dengan pengukuran average time to resolve an incident, yang didapatkan dari data semua tiket insiden pada IT service portal. Data yang diambil adalah jumlah waktu resolusi worksecond dari setiap tiket insiden, dimana worksecond merupakan jumlah waktu yang diperlukan untuk resolusi sebuah tiket insiden dalam satuan detik. Sedangkan untuk pengukuran tingkat kematangan (maturity) fungsi service desk, proses problem management dan proses incident management dilakukan dengan menggunakan ITSM Self-Assesment. Dimana hal tersebut sudah memiliki standar dan kriteria penilaian.

Teknik pengumpulan data primer yang digunakan adalah menggunakan metode atau teknik Focus Group Discussion (FGD). Dimana dengan metode atau teknik Focus Group Discussion (FGD) digunakan untuk mendapatkan data terkait IT maturity dalam hal proses problem management, proses incident management dan fungsi service desk terhadap manajemen organisasi TI Supernova Group secara keseluruhan dengan menggunakan konsep acuan baku yaitu ITSM Self-Assesment. Sedangkan teknik pengumpulan data sekunder yang digunakan adalah menggunakan metode atau teknik observasi. Data sekunder yang berupa laporan rekap detail gangguan perbulan didapat dari IT service portal yang terjadi selama kurun waktu awal tahun 2019 sampai dengan akhir Juni 2020 dan selanjutnya diolah.

Dalam penelitian ini, tidak semua populasi digunakan sebagai objek penelitian yang digunakan untuk mendapatkan indikator baik/buruknya kinerja organisasi TI melalui pengukuran IT maturity dengan konsep ITSM self-assesment. Melainkan menggunakan sampel sebagai objek pengukurannya. Pada periode penelitian ini, populasi karyawan di Supernova Group adalah sejumlah 1309 orang (jumlah tersebut adalah total karyawan grade I sampai dengan grade VIII), dengan jumlah karyawan di organisasi TI adalah 18 orang. Untuk mendapatkan tingkat kepuasan pengguna terhadap layanan TI di Supernova Group dan hal penyebab adanya ketidakpuasan pengguna terhadap layanan TI, yang dijadikan sampel adalah karyawan yang ber-grade IV-VII pada masingmasing periode pengukuran. Untuk mendapatkan data IT maturity dalam penelitian ini, tidak semua karyawan di organisasi TI dilibatkan dalam forum diskusi tertutup (focuss group discussion). Hanya karyawan di organisasi TI dengan grade IV-VII dan karyawan yang berfungsi sebagai service desk yang dilibatkan sebagai informan dalam FGD. Sehingga sampel dalam penelitian ini berjumlah 10 orang. Dan data insiden/problem yang digunakan adalah data insiden/problem yang statusnya sudah ter-close dari IT Service Portal pada periode awal Januari 2019 sampai dengan periode akhir Juni 2020, dalam hal ini sampel 
yang digunakan adalah sama dengan populasi data yang ada.

Adapun metode analisis yang akan digunakan antara lain :

a. Define, pada tahap ini mendapatkan kondisi as is dan to be. Kondisi as is nya adalah tidak tercapainya kepuasan pengguna dalam hal penggunaan layanan TI, sedangkan kondisi to be nya adalah bahwa besar harapan manajemen agar organisasi TI dapat mencapai target minimum pencapaian kepuasan pelanggan guna memaksimalkan peran organisasi TI terhadap efektifitas dan efisiensi bisnis proses perusahaan. Metode analisis yang digunakan adalah GQM (Goal Question Metrics). Dimana pada tahapan ini, manajemen menargetkan resolusi rerata waktu penanganan insiden/problem adalah sebesar 4 jam dan IT maturity organisasi TI di level minimal adalah 2.5 .

b. Measure, pada tahap ini melakukan pengkajian terhadap variabel-variabel yang paling berpengaruh terhadap munculnya permasalahan yang sudah diketahui. Metode analisis yang digunakan adalah Pareto Chart. Selanjutnya setelah mendapatkan pareto variabel-variabel penyebab masalah, dilakukan uji kematangan proses dan fungsi ITIL dengan menggunakan alat ukur ITSM Self-Assesment dari pareto variabel-variabel penyebab masalah dan mengukur average time to resolve an incident untuk mengkaji kinerja organisasi TI. Pengukurannya adalah dengan dilakukan FGD terhadap manajemen TI Supernova Group dengan sampel 10 orang dari total 18 orang. Kuesioner ITSM SelfAssesment terlampir.

c. Analyze, pada tahap ini akan menggunakan data-data yang diperoleh dari tahap measure untuk dianalisa lebih lanjut. Metode analisis yang digunakan adalah dengan menggunakan:

- Gap Analysis, berusaha memahami jurang pemisah yang terjadi diantara kondisi as is dan to be berdasarkan hasil pengkajian ITSM SelfAssesment. Sehingga dapat diketahui apa saja yang menjadi kekurangan utama saat ini untuk mencapai standard maturity.

- Cause and Effect Diagram, berdasarkan hasil gap analysis yang sudah dilakukan, berusaha lebih jelas faktor-faktor apa sajakah yang menjadi penyebab buruknya kinerja service desk, proses problem management dan proses incident management dengan menggunakan tiket-tiket insiden atau problem periode awal tahun 2019 sampai dengan akhir Juni tahun 2020.

- Pareto Chart, setelah permasalahan buruknya kinerja service desk, proses problem management dan proses incident management diketahui, maka analisa selanjutnya adalah menentukan action-action yang diperlukan untuk menyelesaikan permasalahan yang terjadi.

d. Improve, pada tahap ini akan menjabarkan improvement yang tepat dan sesuai rekomendasi 
acuan standar frame work ITIL v.3 dan metode $5 \mathrm{~W}+1 \mathrm{H}$.

e. Control, pada tahap ini menjabarkan bagaimana hasil dari improvement yang sudah dilakukan. Apakah berdampak positif terhadap pencapaian target manajemen dalam hal tingkat kematangan organisasi TI dan resolusi penanganan gangguan. Dan pada akhirnya digunakan sebagai alat kontrol untuk memonitor indeks pencapaian kepuasan pengguna layanan TI.

\section{HASIL PENELITIAN}

adalah

Penelitian dalam Tesis ini permasalahan terkait tidak tercapainya target manajemen Supernova Group secara umum dan target organisasi TI Supernova Group dalam hal pencapaian kepuasan pengguna (internal user) terhadap layanan TI secara khusus. Sejak periode evaluasi pertama sampai dengan periode evaluasi keenam, target pencapaian kepuasan pengguna layanan TI yang sudah ditetapkan manajemen tidak pernah tercapai. Bahkan terjadi tren penurunan dari periode pengukuran triwulan pertama tahun 2019 sampai dengan pengukuran triwulan ke-2 tahun 2020. Dari hal yang sudah dipaparkan di Pendahuluan, didapat hasil bahwa penyebab buruknya kepuasan pengguna terhadap layanan TI adalah karena buruknya kinerja organisasi TI Supernova Group dalam hal memaintain layanan TI yang sudah ada.
Baik dari sisi software maupun hardware-nya. Pareto dari buruknya kinerja organisasi TI disebabkan oleh 3 hal besar, antara lain problem management process, incident management process dan service desk function. Oleh karena itu, untuk menyelesaikan dan mendapatkan rekomendasi perbaikan yang tepat dari fenomena yang terjadi di atas, peneliti menggunakan metode DMAIC untuk mendapatkan process improvement yang tepat dan acuan standar ITSM yaitu frame work ITIL v.3.

Pada Tahap Define, peneliti mendapatkan kondisi as is dan to be dari sasaran penelitian dari pihak manajemen Supernova Group untuk mencapai indeks pencapaian kepuasan pengguna terhadap layanan TI yang sudah ditetapkan, yaitu minimal sebesar 0.80 dari skala 1.00. Pihak manajemen Supernova Group mempunyai harapan dan ekspektasi agar kinerja organisai TI dalam hal penanganan insiden atau problem dapat ditingkatkan menjadi 4 jam, sebelumnya target resolusi penanganan gangguan adalah sebesar 6 jam. Ekspektasi lainnya adalah seluruh fungsi dan proses dari ITIL service operation yang sedang diterapkan dan akan diimplementasikan dapat diperbaiki atau mencapai minimal tingkat kematangan level 2.5, level dimana sebuah organisasi memastikan bahwa aktifitas proses saling terintegrasi telah cukup untuk memenuhi tujuan. 


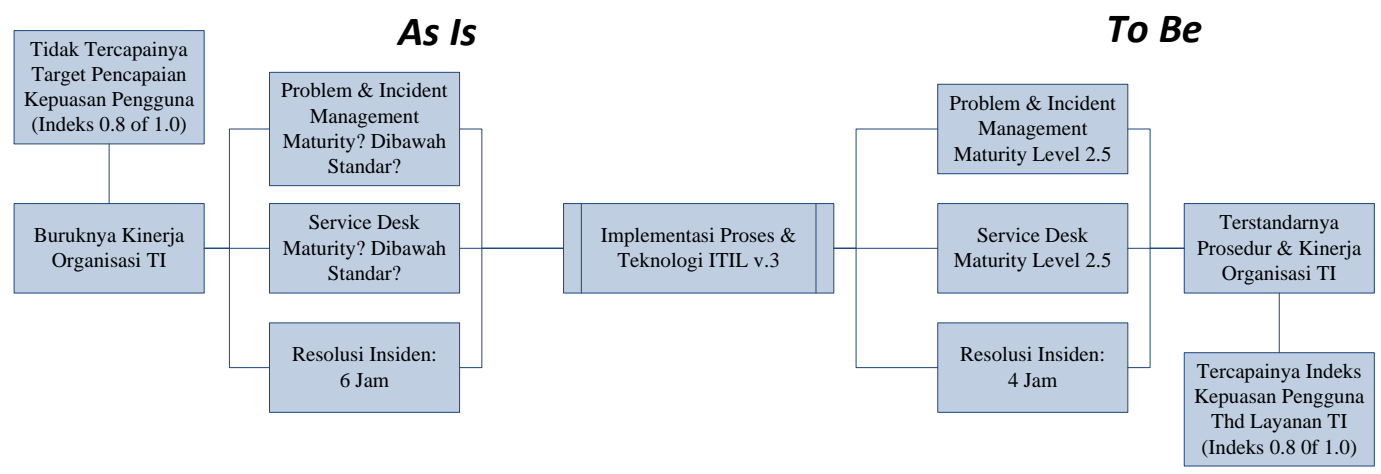

Gambar 4. Harapan Pihak Manajemen Supernova Group Sumber: Data diolah, 2021

Pada Tahap Measure, peneliti akan mengkaji kematangan fungsi dan proses ITIL dengan menggunakan tolok ukur ITSM selfassesment dan mengukur average time to resolve an incident untuk mengetahui kinerja operasi organisasi TI Supernova Group.

Dalam hal untuk mengkaji kematangan fungsi dan proses ITIL dengan menggunakan tolok ukur ITSM self-assesment, untuk mengetahui kinerja operasi organisasi
TI Supernova Group, peneliti mengadakan pertemuan dengan seluruh manajemen dan individuindividu (Focus Group Discussion) dalam organisasi TI Supernova Group untuk melakukan pengkajian serta mendapatkan kondisi tingkat kematangan fungsi dan proses pareto ITIL terhadap ITSM self-assesment. Dalam gambar di bawah berikut, digambarkan hasil assesment untuk masing-masing dimensi dari variabel penelitian.

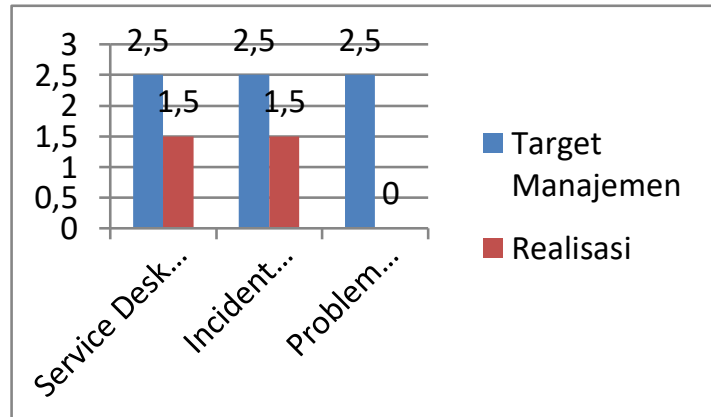

Gambar 5. Hasil Pengkajian Maturity Organisasi TI Supernova Group Berdasarkan Konsep ITSM Self-Assesment

Sumber: Data diolah, 2021

Dalam hal untuk mengukur average time to resolve an incident, untuk mengetahui kinerja operasi organisasi TI Supernova Group, peneliti menggunakan laporan insiden/problem berstatus close dari periode awal Januari 2019 sampai dengan akhir Juni 2020. Dari 994 tiket insiden maka didapatkan nilai ratarata waktu pengerjaan per tiketnya (average time to resolve an incident) adalah sebesar 7,686 jam, dimana ukuran ini memiliki perbedaan yang cukup besar dari ekspektasi manajemen Supernova Group yaitu sebesar 4 jam. 
Pada Tahap Analyze ini, peneliti akan menggunakan data-data yang telah diperoleh sebelumnya dari IT maturity assesment dari service desk function, incident management process, dan problem management process dengan menggunakan konsep ITSM self-assesment dan laporan tiket insiden dari awal Januari 2019 sampai dengan akhir Juni 2020 untuk dianalisa lebih lanjut. Berdasarkan hasil pengkajian ITSM self-assesment yang sudah dilakukan sebelumnya dimana untuk fungsi service desk dan proses incident management samasama memperoleh tingkat kematangan 1.5, sedangkan proses problem management memperoleh tingkat kematangan 0. Dari data berikut, maka dapat diketahui gap pada ITSM self-assesment yang perlu dilengkapi agar dapat mencapai tingkat kematangan 2.5 seperti yang diharapkan pihak manajemen Supernova Group sebelumnya. Peneliti bersama informan (narasumber) organisasi TI Supernova Group telah mengidentifikasi dan mengkategorikan gap tersebut. Gap yang diidentifikasi adalah gap yang bersifat kritis (mandatory). Dari masing-masing dimensi yang sudah diketahui identifikasi gap-nya, maka menghasilkan 4 kategori permasalahan yang dijelaskan pada tabel berikut ini:

Tabel 2. Kategori Permasalahan dari GAP Analysis

\begin{tabular}{ll}
\hline \multicolumn{1}{c}{ Proses } & \multicolumn{1}{c}{ Deskripsi } \\
\hline Problem Management & $\begin{array}{l}\text { Belum adanya problem management process untuk mengatasi } \\
\text { problem yang ada }\end{array}$ \\
\hline & $\begin{array}{l}\text { Adanya permasalahan pada incident identification, dimana belum } \\
\text { memiliki prosedur untuk menerima laporan insiden melalui telepon } \\
\text { dan belum memiliki prosedur yang jelas untuk menentukan prioritas } \\
\text { tiket insiden }\end{array}$ \\
\hline $\begin{array}{l}\text { Configuration } \\
\text { Management }\end{array}$ & $\begin{array}{l}\text { Belum memiliki library terpadu untuk semua produk layanan TI baik } \\
\text { itu software, hardware, user manual dan lain sebagainya }\end{array}$ \\
\hline & $\begin{array}{l}\text { Belum memiliki perjanjian kerja mengenai support layanan TI yang } \\
\text { jelas antar fungsi pada organisasi TI Supernova Group dan demikian } \\
\text { juga pihak ketiga }\end{array}$ \\
\hline
\end{tabular}

Sumber: Data diolah, 2021

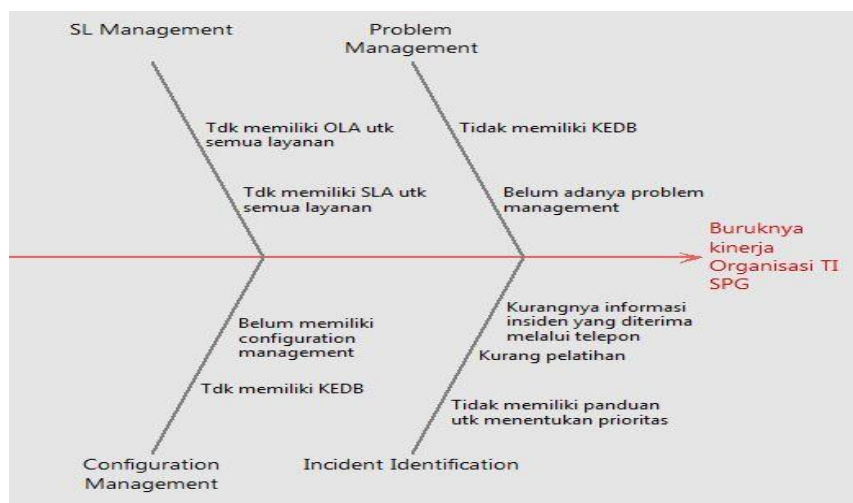

Gambar 6. Cause and Effect Diagram Buruknya Kinerja Organisasi TI Sumber: Data diolah, 2021

Selanjutnya dari 4 kategori di insiden/problem yang terjadi. Dengan atas, didetailkan dengan fakta acuan adalah laporan insiden 
berstatus close periode awal Januari 2019 sampai dengan akhir Juni 2020. Berdasarkan hasil analisa, peneliti bersama informan (narasumber) dari FGD berusaha untuk mengidentifikasi akar penyebab permasalahannya dengan menggunakan alat bantu QCC yaitu cause \& effect diagram. Dan berikut ini diilustrasikan pada Gambar 6.

Pada Tahap Improvement ini, peneliti berdasarkan hasil analisa diagram fishbone di atas melakukan
FGD dengan manajemen organisasi TI Supernova Group untuk mendapatkan improvement yang tepat yang penyelesaiannya disesuaikan dengan kategori permasalahan yang didapatkan. Langkah perbaikan dalam jangka pendek, menengah dan panjang yang dijabarkan di bawah berikut adalah hasil dari rekomendasi dari kegiatan FGD tahap kelima terhadap manajemen organisasi TI Supernova Group dengan pedoman dari frame work ITIL v.3.

Tabel 3. Langkah Perbaikan Jangka Pendek

\begin{tabular}{cl}
$\begin{array}{c}\text { Kategori } \\
\text { Permasalahan }\end{array}$ & \multicolumn{1}{c}{ Action } \\
\hline \multirow{2}{*}{$\begin{array}{c}\text { Mroblem } \\
\text { Management }\end{array}$} & $\begin{array}{l}\text { Memulai proses problem management dengan menggunakan tiket request } \\
\text { fullment dan membuat kategori baru problem management }\end{array}$ \\
\cline { 2 - 2 } & \begin{tabular}{l} 
Menampung known error pada sebuah file di dalam sharing folder \\
\cline { 2 - 2 } Mulai mengatasi problem yang telah diidentifikasi pada tahap analisa \\
cause and effect dan meninjau ulang pada setiap monthly meeting
\end{tabular} \\
\hline
\end{tabular}

Sumber: Data diolah (FGD Tahap V), 2021

Tabel 4. Langkah Perbaikan Jangka Menengah

\begin{tabular}{|c|c|}
\hline $\begin{array}{c}\text { Kategori } \\
\text { Permasalahan }\end{array}$ & Action \\
\hline \multirow{4}{*}{$\begin{array}{c}\text { Problem } \\
\text { Management }\end{array}$} & Merancang penyesuain proses incident management \\
\hline & Merancang proses problem management \\
\hline & Merancang KEDB \\
\hline & $\begin{array}{l}\text { Mengembangkan aplikasi IT service portal untuk menunjang proses } \\
\text { problem management dan KEDB }\end{array}$ \\
\hline SLA Management & $\begin{array}{l}\text { Menetapkan jalur eskalasi untuk setiap layanan TI, tim technical support } \\
\text { atau pihak ketiga siapa saja yang seharusnya memberikan support } \\
\text { apabila terjadi insiden }\end{array}$ \\
\hline \multirow{4}{*}{$\begin{array}{l}\text { Incident } \\
\text { Identification }\end{array}$} & $\begin{array}{l}\text { Membuat panduan phone script untuk memperoleh informasi pada saat } \\
\text { menerima laporan insiden melalui telepon }\end{array}$ \\
\hline & $\begin{array}{l}\text { Memberikan pelatihan mengenai panduan phone script kepada tim } \\
\text { service desk }\end{array}$ \\
\hline & $\begin{array}{l}\text { Memperjelas cara untuk menentukan prioritas dari sebuah laporan } \\
\text { insiden }\end{array}$ \\
\hline & $\begin{array}{l}\text { Memberikan pelatihan cara menentukan prioritas insiden kepada tim } \\
\text { service desk }\end{array}$ \\
\hline
\end{tabular}

Sumber: Data diolah (FGD Tahap V), 2021

Tabel 5. Langkah Perbaikan Jangka Panjang

\begin{tabular}{|c|c|}
\hline $\begin{array}{c}\text { Kategori } \\
\text { Permasalahan }\end{array}$ & Action \\
\hline $\begin{array}{l}\text { Configuration } \\
\text { Management }\end{array}$ & $\begin{array}{l}\text { Mencari aplikasi CMS yang dapat memenuhi kebutuhan configuration } \\
\text { management }\end{array}$ \\
\hline \multirow[b]{2}{*}{ SLA Management } & Menentukan OLA antar departemen untuk setiap layanan TI \\
\hline & $\begin{array}{l}\text { Memperbarui kontrak dengan pihak ketiga pada saat perpanjangan kontrak } \\
\text { dengan menambahkan komponen SLA }\end{array}$ \\
\hline
\end{tabular}


Sumber: Data diolah (FGD Tahap V), 2021

Selanjutnya peneliti akan menjabarkan pengembangan yang dilakukan atas keenam langkah perbaikan (dari 15 improvement yang direkomendasikan), dimana peneliti ikut terlibat didalamnya dan dapat dirangkum pada tabel berikut ini:

Tabel 6. Rangkuman Pengembangan Proses \& Teknologi Penelitian

\begin{tabular}{ll}
\hline \multicolumn{1}{c}{ Judul } & \multicolumn{1}{c}{ Langkah Perbaikan } \\
\hline $\begin{array}{l}\text { Penentuan prioritas } \\
\text { insiden }\end{array}$ & $\begin{array}{l}\text { Memperjelas cara untuk menentukan prioritas dari sebuah laporan } \\
\text { insiden }\end{array}$ \\
\hline $\begin{array}{l}\text { Panduan handling user } \\
\text { complaint }\end{array}$ & $\begin{array}{l}\text { Membuat panduan phine script untuk memperoleh informasi pada } \\
\text { saat menerima laporan insiden melalui telepon }\end{array}$ \\
\hline \multirow{2}{*}{ Pengembangan proses } & Merancang penyesuain proses incident management \\
\cline { 2 - 2 } & Merancang proses problem management \\
\cline { 2 - 2 } Pengembangan teknologi & $\begin{array}{l}\text { Mengembangkan aplikasi IT service portal untuk menunjang proses } \\
\text { problem management dan KEDB }\end{array}$ \\
\hline Sumber: Data diolah, 2021 &
\end{tabular}

Pada Tahap Control ini, peneliti mengukur kembali tingkat kematangan proses dan fungsi ITIL dengan menggunakan ITSM selfassesment pada fungsi service desk, proses incident management dan problem management, kemudian peneliti juga akan mengukur kembali kinerja organisasi TI dengan menggunakan ukuran average time to resolve an incident. Dan untuk memperjelas kondisi tiket insiden sebelum dan sesudah pengembangan dilakukan, peneliti akan membandingkan data tiket insiden tersebut pada 4 kategori permasalahan yang telah ditemukan pada tahap analisa sebelumnya. Peneliti mengadakan pertemuan dengan informan (narasumber) dari kegiatan FGD yang diadakan sebelumnya untuk melakukan pengkajian terhadap ITSM self-assesment kembali setelah dilakukan pengembangan proses dan teknologi di Organisasi TI Supernova Group. Gambar di bawah berikut menunjukkan hasilnya.

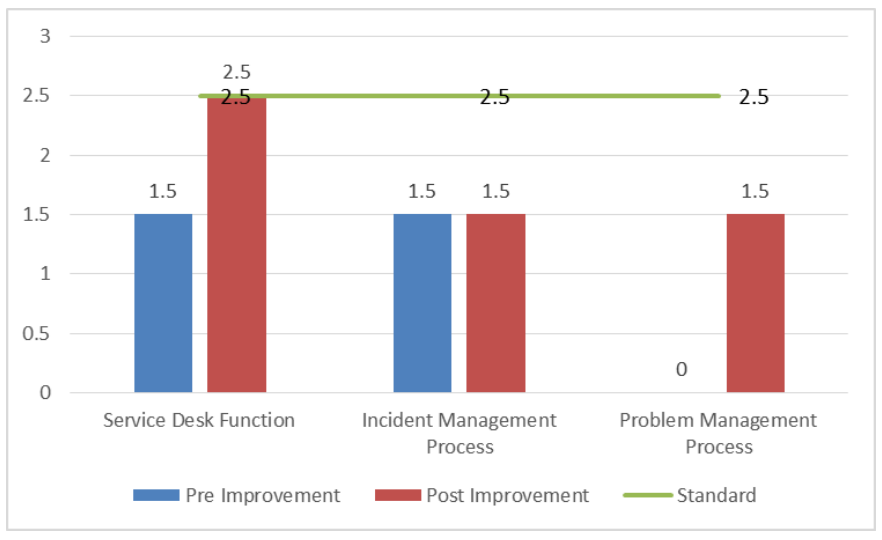

Gambar 7. Hasil Pengkajian ITSM Self-Assesment Akhir Sumber: Data diolah, 2021

Kemudian peneliti insiden yang terjadi pada awal bulan menggunakan semua data tiket Januari tahun 2021 sampai dengan 
akhir bulan Maret tahun 2021 dari IT service portal yang berjumlah 137 tiket insiden. Kemudian data dipersempit dengan hanya mengambil data yang sudah memiliki status closed dan hanya diselesaikan oleh fungsi service desk saja, sehingga data yang akan diolah hanya menjadi 100 tiket insiden, dan nilai rata-rata waktu pengerjaan per tiketnya (average time to resolve an incident) adalah 4.884 jam. Meskipun masih belum mencapai harapan dari pihak manajemen Supernova Group yakni sebesar 4 jam, namun kinerja organisasi TI Supernova Group telah mengalami peningkatan sebesar 2.802 jam, dari sebelumnya 7.686 jam.

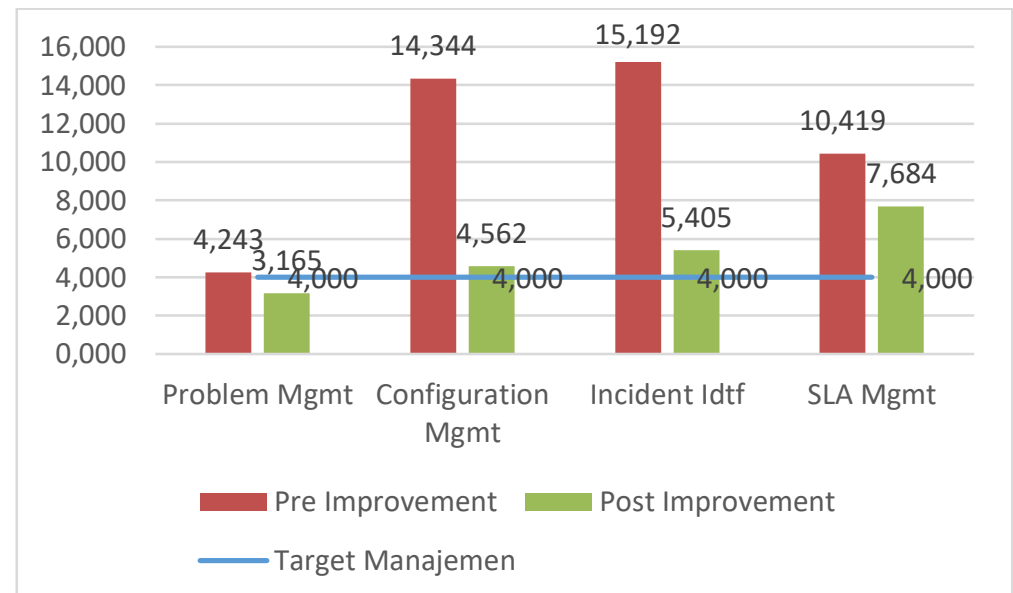

Gambar 8. Perbandingan Sebelum \& Sesudah Improvement Data Insiden Sumber: Data diolah, 2021

\section{KESIMPULAN}

Kesimpulan yang didapat dari penelitian ini antara lain:

1. Hasil assessment terhadap tingkat kematangan organisasi TI Supernova Group dalam hal problem management process, incident management process dan service desk function adalah berurutan berada di level 0, 1.5 dan 1.5. Dan rerata resolusi penanganan gangguan adalah sebesar 7.686 jam. Dimana dua hal tersebut adalah penanda indikator buruknya kinerja organisasi TI Supernova Group yang pada akhirnya berdampak pada buruknya pencapaian kepuasan pengguna internal.
2. Buruknya IT performance organisasi TI Supernova Group adalah disebabkan tidak adanya OLA \& UC untuk semua layanan, tidak adanya KEDB, tidak adanya problem management, tidak adanya configuration management, kurangnya informasi insiden yang diterima melalui telepon, kurangnya pelatihan seta tidak adanya panduan untuk menentukan prioritas insiden.

3. Cara/upaya perbaikan yang direkomendasikan untuk memperbaiki permasalahan buruknya kinerja TI antara lain penentuan prioritas insiden, penyusunan user call handling complaint, perancangan penyesuaian proses incident 
management, perancangan proses problem management \& KEDB dan pengembangan aplikasi IT service portal untuk mendukung problem management dan KEDB.

4. Upaya perbaikan yang dilakukan dari beberapa hal improvement yang didapatkan menghasilkan beberapa hasil antara lain adanya peningkatan tingkat kematangan dalam hal service desk function dari 1.5 menjadi 2.5 (tercapai) dan problem management process dari 0 menjadi 1.5 (belum tercapai). Dalam hal incident management process, masih belum terjadi perubahan tingkat kematangan. Kondisi sebelum dan sesudah di tingkat kematangan 1.5 (belum tercapai). Sedangkan rerata resolusi penanganan gangguan adalah sebesar 4.884 jam (belum tercapai).

\section{DAFTAR PUSTAKA}

Aazadnia, M., \& Fasangsari, M. (2008). Improving the Information Technology Service Management with Six Sigma. IJCSNS International Journal of Computer Science and Network Security, VOL.8 No.3, March 2008, 144-150.

Alshany, M. M., Elfakharany, E., \& Elaziem, M. A. (2012). Information Technology Service Management (ITSM) Implementation on Information Technology Infrastructure Library Ver.3 (ITIL V3). International Journal of Business Research and Management (IJBRM), Volume 3: Issue (3).

Cater-Steel, A., Toleman, M., Tan, Wui-Gee.

(2006).
Transforming IT Service Management - The ITIL Impact. 17th Australasian Confrence on Information Systems.

Chan, P. C., Durant, S. R., Gall, V. M., \& Raisinghani, M. S. (2008). Aligning Six Sigma and ITIL to Improve IT Service Management. International Journal of E-Services and Mobile Applications (IJESMA), Vol 01, 62-82.

Gacenga, F., Cater-Steel, A., Toleman, M., \& Tan, Wui-Gee. (2011). Measuring the Performance of Service Oriented IT Management. Working Paper on Information Systems, ISSN 1535-6078.

Harris, Michael. D., Herron, David. E., \& Iwanicki, Stasia. (2004). The Business Value of IT : Managing Risk, Optimizing Performance, and Measuring Results. An Auerbach Book.

Kang, H., \& Bradley, G. (2002). Measuring the Performance of IT Services: an Assesment of ServQual. International Journal of Accounting Information, Systems 3 (2002) 151-164.

Lahtela, A., Jantti, M., \& Kaukola, J. (2010). Implementing an ITILBased IT Service Management Measurement System. Digital Society, 2010. ICDS '10. Fourth International Conference (hal. 249-254). St. Maarten: IEEE.

Nurjaya, N., et al. (2021). Pengaruh Kompetensi Sumber Daya Manusia Dan Kemampuan Pemanfaatan Teknologi Terhadap Kinerja Aparatur 
Desa Pada Kantor Kepala Desa

Di Kabupaten Gunungkidul, Yogyakarta. JENIUS (Jurnal Ilmiah Manajemen Sumber Daya Manusia), 4(3), 332-346.

Potgieter, B. C., Botha, J. H., Lew, C. (2004). Evidence that Use of The ITIL Framework is Effective.

Stanwick, P., \& Stanwick, S. (2002). IT Performance: How Do You Measure a Moving Target?. The Journal of Corporate and Accounting, Wiley InterScience.

Talla, M., \& Valverde, R. (2013). An Implementation of ITIL
Guidelines for IT Support

Process in a Service

Organization. International

Journal of Information and Electronic Engineering, Vol 3, No 3, 334-340.

Wong, W. Y., Lee, C. W., \& Tshai, K. Y. (2012). Six Sigma in IT Process, IT Services and IT Products: A Fact or a Fad? Six Sigma Beyond Manufacturing in IT Processes, IT Services and IT Products. Computer and Information Technology (CIT), 2012 IEEE 12th International Conference (hal. 524-531). Chengdu: IEEE. 